\title{
Exploring Change and Innovation by ICT Teaching Staff in the New Zealand Polytechnic Sector
}

\author{
Christo Potgieter \\ Waikato Institute of Technology, New Zealand
}

itbcp@wintec.ac.nz

\begin{abstract}
Papers presented at the 2003 conference of HERDSA (Higher Education Research and Development Society of Australasia) proposed guidelines for change and innovation in higher education. This paper empirically studied these guidelines in the ICT environment of an institution. We explored change and innovation outputs by ICT staff at ITPs (Institutes of Technology and Polytechnics), aspects of the environment in which ICT staff work and the leadership of that environment. It appears that the particular environment does not emphasize change and innovation that one would typically expect of the ICT environments. Staff perceptions indicate that change and innovation are not highly emphasized and visibly lead by management. We advise on ways that leadership could create this environment. Empirically study of the organization for change and innovation by ICT staff will require further development of instruments that considers the observations made in this project.
\end{abstract}

Key words: ICT Teaching, ICT Change and Innovation, Performance Criteria, Policy

\section{Increased Change and Innovation Management}

A report from the World Economic Forum by Paua (2003) indicates that the diffusion of ICT continues across the world, with very high and dynamic growth in some countries. Australia and New Zealand are among the list of top 10 countries in some of the categories. The report indicates four policy imperatives for countries, one of which is a recommendation for more focus on education and allocation of sufficient resources.

In New Zealand, "Innovation" is one of government's six national goals relating to the development of a "Knowledge Society". The ITPs (Institutes of Technology and Polytechnics) support change and innovation in general. While not specifically referring to ICT, the Charter and Profile document of the ITP sector (2003) implies support of an environment of ICT exploitation in several ways. For example it emphasizes the ability to anticipate, embrace and lead change that is critical to the responsiveness of the sector and it underlines the need for innovative vocational training in their Vision statement, which is often required for ICT. The Charter and Profile document also reflects encouragement and reward for innovation and creativity, and support for proactiveness in developing programmes relevant to changing needs, in their Values statement. And

Material published as part of this journal, either on-line or in print, is copyrighted by Informing Science. Permission to make digital or paper copy of part or all of these works for personal or classroom use is granted without fee provided that the copies are not made or distributed for profit or commercial advantage AND that copies 1) bear this notice in full and 2) give the full citation on the first page. It is permissible to abstract these works so long as credit is given. To copy in all other cases or to republish or to post on a server or to redistribute to lists requires specific permission from the publisher at Publisher@InformingScience.org finally does the Charter and Profile document include innovativeness as one of six key strategies when stating "Imagine, think, act and deliver those programmes and services which break new ground, challenge accepted norms and have the capacity to set new directions". There is support for 
innovation at national levels.

Several of the papers at the 2003 educational conference of the Higher Education Research and Development Society of Australasia (HERDSA) explored the increased management of change at higher education institutions (e.g. Kenny, 2003; Huntley-Moore \& Panter, 2003; Van Schoor, 2003). ITPs have been going through major changes since the late 1990's due to changes in funding by government. Change and innovation management by higher education institutions therefore appear to be a very relevant field of study for ITPs. Change and innovation is likely to be expected from each area in differing degrees. But how does academic staff operate?

Bates (2000) noted that academic/teaching staff members (educators) operate as independent professionals in relation to their teaching. When change is managed in these educational environments, several key points must be addressed. Most important is an appreciation of how educators interact with their peers, adapt to change and grow professionally. The independent nature of academic work, impacting on educational innovation, is also a major consideration. Education staff also needs time for interpretation, understanding and adoption during implementation. And finally does the full implication of educational innovation only emerge during implementation of these innovations. The involvement of teaching staff must therefore be encouraged during the whole process, lest resistance impede necessary change.

An educational innovation is likely to require that new understandings and skills be incorporated into teaching practice (Kenny, 2003). This requires teacher change which comes about "when the teachers themselves consciously examine their own activities and critically reflect upon their own practice, their situational constraints in which they work and the consequences of their action". Given the independent work of teachers, the need to change teaching practice requires the involvement of the practitioners themselves, who can study their own practices and determine how these might best adapt to requirements for change. Past research (e.g. Gilbert, 1994; Walker, 1993) has shown that this reflective practice is a common way in which teachers improve their own practice, so extending this model to incorporate needed change would not use unfamiliar processes.

In ITPs, the heads of departments are typically the change managers, linking the teaching environment of teachers with strategic management, though they sometimes drive change rather than just managing it (Bruce-Ferguson, 1999). They are the people who should know how to lead change initiatives. Potgieter and Bruce-Ferguson (2003) explored the implications for heads of department of ITPs in general. It is likely that the change for ICT heads of department will even be higher, considering the nature of ICT, the dynamics of the ICT industry, changes to ICT teaching environment and the organizational growth in the academic ICT environment at higher education institutions (Potgieter \& Jansen van Vuuren, 2003).

\section{Organizing for Change and Innovation}

Kenny (2002) reported on key success factors for projects involving radical change in educational environments. Apart from the usual issues of clear support from senior management and sufficient time, two other items are imperative for success in educational environments. The establishment of several self-managed project teams with open communication processes, conducting action learning/action research, is very important. Linked to this is accountability processes emphasizing documentation of learning, iterative development, periodic reporting after each research cycle and dissemination to the organization.

Kenny explains that the emphasis is not solely on achievement of goals, but also on learning. Projects start with a planning phase, continue with a design and development phase and conclude with an evaluation phase. These might appear to be the same as other change projects, but project occurrences are more frequent (with smaller targets) and each project contains high provision for 
learning experiences. The sequence follows a common action research cycle, and is practised in a range of environments.

This approach has been followed with success during an action research project in an IT department of a bank in South Africa (Potgieter, 1997). Many aspects of the above principles were also used with success during the change and innovation initiatives of an IT department at an Institute of Technology in South Africa (Potgieter \& Herselman, 2003). That particular educational institution is still busy with major developments towards becoming a University of Technology after following the formation of a Faculty of ICT from development in recent years.

Bruce-Ferguson $(1999,2003)$ described how academic staff and heads of departments at ITPs are faced with the challenges to do and manage research along with other activities, and the stresses this situation can cause. These challenges are often not appreciated by non-academic management at ITPs. Change management to develop a research culture at an ITP institution is clearly a mission in itself! Potgieter and Bruce-Ferguson (2003) asked whether there is a need to assist heads of department at ITPs manage change and innovation. The same could perhaps be asked regarding academic staff, especially academic staff involved in ICT courses.

So far, we have presented issues arising from the research literature that suggest change and innovation skills need to be resident in ICT academic staff. We now argue that the performance criteria of ICT staff should reflect their responsibilities to change and innovate. We will now explore the situation at a specific ITP institution using the documentation negotiated with the union less than three years ago. About $80 \%$ of the ICT teaching staff members are also members of the union.

\section{Staff Performance Criteria}

We assessed the documentation of Performance Criteria at one institution, looking particularly for direct or indirect references to requirements to perform change and innovation. At this institution, the performance criteria were negotiated with the national staff union a few years ago and are still in use. They are also applied to non-union members when considering promotion of academic staff.

Three levels of job grades exist for academic staff. For the purposes of this paper the most junior job level is simply referred to as ASM (Academic Staff Member). This is then followed by Senior ASM (SASM) and Principal ASM (PASM). Each has increased/additional duties and performance requirements. We will consider the role of PASMs because one would expect senior staff to be performing and leading most of the change and innovation.

The Performance Criteria are described in the following categories of duties, namely Generic, Discipline/Subject Area, Teaching and Learning, and Professional Commitment. It is interesting to note that teaching dominates in the document, with extremely little reference to the Research and Entrepreneurship. This emphasis does not encourage ITPs to grow research and to become more entrepreneurial.

The Performance Criteria document is eight pages long (describing requirements for three grades of staff) and covers roughly 100 points that could be considered for references to change and innovation. However, only 14 of the items can really qualify as being direct descriptions of change and innovation. A few extreme examples include "Demonstrate introducing and innovative strategy", "Demonstrate innovation and/or leadership in developing or maintaining effective styles and methods of teaching and learning...", "... renews programmes and courses", "Leads curriculum design and development" and "Demonstrates a commitment to continuous learning".

Some of the other statements that appear to maintain the current order, could, in fact, imply some changes and innovations occurring. Examples include references to "Maintains currency...", 
"...leadership in...planning", "leads...in assessment and moderation processes" and "Significant enhancement of the Polytechnic's reputation". It could be accepted that some change and innovation might be implied from these statements.

In summary very little reference is made to change and innovation. Whatever the outcome, it is still interesting that no special effort was made to emphasize change and innovation. Despite this many staff members do demonstrate these skills as is reflected in the contributions they make to their particular discipline at national level, as will now be illustrated.

\section{Change and Innovation by ICT Teaching Staff}

Change in the ICT field of higher education was also explored by Roberton and Ross (2003) at the 2003 IT educational conference of NACCQ. They indicated how ITPs changed the portfolio of IT qualifications they offer and especially what is planned. At the same conference other authors reported experiences related to change and innovation. In one case it was reported how the portfolio of offerings changed during the past two years with the introduction of several new ICT specialization degrees (Potgieter \& Jansen van Vuuren, 2003). Another paper reported on the development of a new Faculty of ICT (Potgieter \& Herselman, 2003). These papers indicate the changes that are still under way internationally.

What are the changes and innovations that ICT departments at ITPs are already involved in? A simple analysis of the proceedings of the NACCQ 2003 conference shows that about $40 \%$ of the papers focused primarily on teaching, up to $45 \%$ on improved understanding of ICT (mostly for the purposes of teaching) and the rest on matters regarding practicing research and management. This is a rough breakdown and estimate, but it does indicate that ICT teaching staff members spend ample time working on the complexities of ICT itself. These outputs most often do not yet increase the richness of the ICT technology (subject field for non-teaching) similar to the research outputs of other ICT researchers.

ICT staff at ITPs are challenged by many matters to change and innovate when teaching. Following below is an overview of the type of work ICT teaching staff are involved with, with examples of the papers of specific authors that can be found in the conference proceedings of the 2003 conference of the New Zealand National Advisory Committee on Computing Qualifications (NACCQ, 2003):

- New ICT technologies to be covered in courses - The 18-month cycle for doubling of the capability of ICT is a well-known observation that impacts rather uniquely on ICT staff (e.g. Albertyn, 2003; Clark \& Roper, 2003; Harvey; Jamieson, 2003; Kennedy, 2003; McLay; Nisse, Whiddett, \& Atkins, 2003; Pears \& Mansfeld, 2003; Robbins, 2003; Roggio, 2003; Strode, 2003; Wen, Sathu, \& Joyce, 2003)

- New technologies to be used for teaching - ICT students increasingly demands that teaching staff use ICT in their teaching, especially to demonstrate how ICT works while also being flexible with room arrangements (e.g. Young \& Huggard, 2003)

- Increasing ICT proficiency of a group of students at entry levels - The number of students with highly advanced self-taught ICT skills increases each year, demanding changes from the tutor/lecturer (e.g. Kearry \& Skelton (2003) on teaching to students of the "Playstation era")

- Increasing number of ICT students with low ability - We also have more students in class (due to financial and social reasons) that cannot always cope. They require extra teaching effort and activities not previously required, as well as special consideration of literacy (e.g. Mann, Davies, \& McGregor, 2003) 
- Improving success rates (internationally problematic in ICT studies) - Ministry of Education $(\mathrm{MoE})$ indicated that they intend changing funding formulas to reduce funding for institutions where student pass rates are low. Improvements will require more effort from teaching staff many areas

- Changes to accommodate different learning styles - This does perhaps apply to many study fields, but studies by Burrell (2003) indicate that ICT teaching has its own challenges, that are increasing

- Increased portion of non-English speaking students in class - Internationalisation is experiences by many institutions worldwide, bringing its challenges regarding language and cultures (e.g. Chamberlain \& Hope, 2003; Connolly \& Cleary, 2003)

- Adult learners in ITP environment hold their own challenges that should be considered and be adjusted to (e.g. Hu, 2003; Li, 2003)

- Increased class sizes for institutional profitability - Reports from the Tertiary Advisory Monitoring Unit (TAMU, 2002) indicate that ITPs are gradually increasing average class sizes, moving away from the niche for which staff were trained for many years

- Flexible teaching - The number of ICT students dropped at many ITPs, resulting in classes that are half-full where innovative approaches are use to avoid overload of staff that must now teach more classes for institutional profitability

But the changes and innovations are not limited to the well-known teaching duties - pressures requiring change and innovation surprisingly include many non-teaching duties. For example, ITP staff members generally have a high teaching load (12-14 hours per week when teaching fulltime on the degree), leaving little time for research. This implies that less time is available to create the environment from which they could benefit (e.g. Bruce-Ferguson, 1999, 2003). ITPs must also increasingly compete with universities for research money because of recent changes to government funding by the creation of the Performance Based Research Fund (PBRF). New qualification structures must continuously be introduced to meet market needs and new ICT courses are introduced annually with qualifications reviewed and changed probably much more than other fields of study (e.g. Roberton \& Ross, 2003; Potgieter \& Jansen van Vuuren, 2003). It is also expected of ITPs to increasingly imbed industry qualifications provided by IT vendors (for example by Microsoft and CISCO) into ITP qualifications (see Pascoe, 2003).

There are more changes and innovations. For example, many students who started their ICT studies at Private Training Institutions (PTE's) in New Zealand since 2001 and now want to continue with further studies at ITPs. When it became clear that the specific use of unit standards of NZQA resulted in some complications when wanting to allow students to continue their studies at ITPs, transition arrangements had to be developed. Furthermore is tutor time for hands-on teaching and skills development in laboratories at ITPs higher than at universities - this is after all one of the major differences between the two types of institutions. And finally is government gradually increasing administrative requirements such as more comprehensive programme reviews, controls of changes to degrees, reporting requirements and contributions required for social responsibilities.

It appears that ICT teaching staff at ITPs are generally involved in much more change and innovation than might appear from the performance criteria. The indicators of change and innovation we extracted from the performance criteria documentation, were in fact only focusing on the most senior staff. Staff from the institution where job descriptions were analyzed in the previous section contributed richly to NACC annual conferences over previous years while these job descriptions were already used at the institution. The question now is - what is the role of management? 


\section{Leadership by the Head of Department}

Change and innovation is essential for the ICT teaching environment. This requires appropriate leadership and clear understanding by staff about the role of managers in change and innovation. This is especially true in the academic environment where most change and innovation appears to be performed by the academic staff, and not managers. For this purpose, we need to consider staff perceptions and their expectations about the roles of the different levels of management.

The Head of Department (HOD) is typically a person that would qualify for appointment at the level of PASM based on academic achievement and leadership. In reality he/she performs fulltime administrative management of a department with 25-40 members of staff. Some of the roughly 15 HODs were promoted through the academic ranks of the institution and others were appointed from the academic ranks of other institutions. A few HODs have extensive experience in a non-academic industry. Each department appointed three to six programme leaders to manage the student and programme administration of each of the programmes in the department as a part of the duties. This is typical of the ITP sector in New Zealand. HODs are considered to be part of the management team of the institution and cannot be represented by the academic or support staff unions of staff. However, they are included in the totals when calculating efficiency ratio's of academic departments. A maximum of six HODs report to one Dean.

\section{Job Description of the HOD}

"Primary Objectives" in the job description document of HOD do not specifically refer to the need for growth, change or innovation. It refers to leadership to ensure that the needs of students and industry and met; that strategic and business plans, as well as teamwork and a culture of excellence, are developed; and that fiscal responsibility is maintained. Fortunately, reference is made to "continuous improvement" as part of a team culture and support of the drive of government for the tertiary sector. Unfortunately, no reference is made to the required permanent existence of flexibility and innovative capabilities to ensure long-term survival and growth.

Key tasks for HODs include the traditional matters of Leadership, Department Management, Programme and Course Management, Financial and Resource Management, and People Management. These are each explored briefly now. Only two of the seven performance indicators of Leadership could be related to change and innovation, namely "Developing responses to resource management issues when evaluating and allocating resources in pursuit of goals and objectives" and "Management decisions should encourage the achievement of strategic and business plans". One of the performance indicators refers to the articulation of vision and direction and another to the importance of ensuring that staff members understand their role and contributions.

The key task of Department Management looks much worse. None of the nine performance indicators mention the need to manage change and innovation or reflect the importance of causing and managing change and innovation. Compliance with institutional rules appears to be very prominent, namely ensuring business plans are developed and implemented, adherence to requirements of $\mathrm{OSH}$ and internal policies and rules. Marketing, relationship management with support functions and networks with the external environment are also referenced as activities to be undertaken.

The same holds for Programme and Course management, Financial Resource Management and People Management where none of the performance indicators mention the need to manage change and innovation or even reflect the importance of causing and managing change and innovation. It may however be implied by references to for example ensuring profitability, ongoing curriculum revision and professional renewal of staff. 
A list of 17 behavioral indicators are also associated with the job description. Some of the items can be associated with the necessity to manage change and innovation. For example there is reference to the requirement that the HOD should be a "practitioner of continuous improvement", he/she must "adjust readily to meet changes in the work environment" and must also "view learning as an ongoing process". Specific mention is fortunately made to requirements regarding the "ability to be innovative, question the status quo, anticipate and initiate change" but it stops short of following through to implementation (i.e. full innovation). But specific references to the ability to manage change and innovation through staff in the department and institution would have been beneficial to indicate appropriate leadership.

In summary, the job description contains very little reference to change and innovation management. This might be the result of a deliberate decision made by the institution based on the traditional uses of these instruments to define roles and responsibilities for staff. It is however very unlikely that an institution would be very appreciative of the importance of change and innovation management but then not emphasize it in the documentation. It appears more likely that increasing pressures on the institution are causing senior management to focus more on traditional management rather than innovative management requirements for their heads of department, as revealed in the above generic job description.

This apparent lack of demonstration of appreciation of the importance of the role of heads of department in change and innovation management may result in institutional unawareness of the complexities of managing change and innovation. This might result in practices where major change initiatives are generally still dealt with as typical industrial change management initiatives instead of action learning initiatives, as advocated by Kenny (2003) and Van Schoor (2003).

\section{Literature and Three Perspectives on the Role of HODs}

How does above empirical view at one institution compare the literature about the role of HODs?

The tasks in above job descriptions hold similarities to the overviews used by Huntley-Moore and Panter (2003), the views of staff at the institution and the views of an HOD of one department (and author of this paper). Figure 1 summarizes the perspectives.

Huntley-Moore and Panter constructed their categories from literature and personal experience, and then they used it for surveying at the institution they were employed at. The "Job Description" was in practical use at the institution. It was also used as reference when interviewing the current HOD of the department during 2002, by the application for self-assessment for the interview and for performance reviews. The "Staff Perspective" was obtained during a departmental planning workshop in September 2002 on request of the acting HOD who was new to the management of academic units. And information in the column for the view of the HOD was recorded by the current HOD who has several years of overseas experience in similar positions and presented to staff of the department at several meetings during 2003.

We can make a few key observations from the summary above. There is relative agreement about the HOD's involvement in matters regarding Finance, Staff, Programme/Courses and Research, which possibly indicates common ground. We also notice that the list of the current incumbent ("HOD perspective") is longer than that of the other perspective, effectively encompassing all of them. The HOD's personal list also includes a category for Institutional Service, such as involvement in forums and projects beyond the department. This might be unique to the institution however. Documentation of the sources does not indicate exactly what is expected of the HOD as far as matters regarding change and innovation is concerned. Of course we assume that is implied, especially in the formal job descriptions. And, finally is it noteworthy to mention that the survey of Huntley-Moore and Panter (2003) indicated that most HODs felt challenged by the 


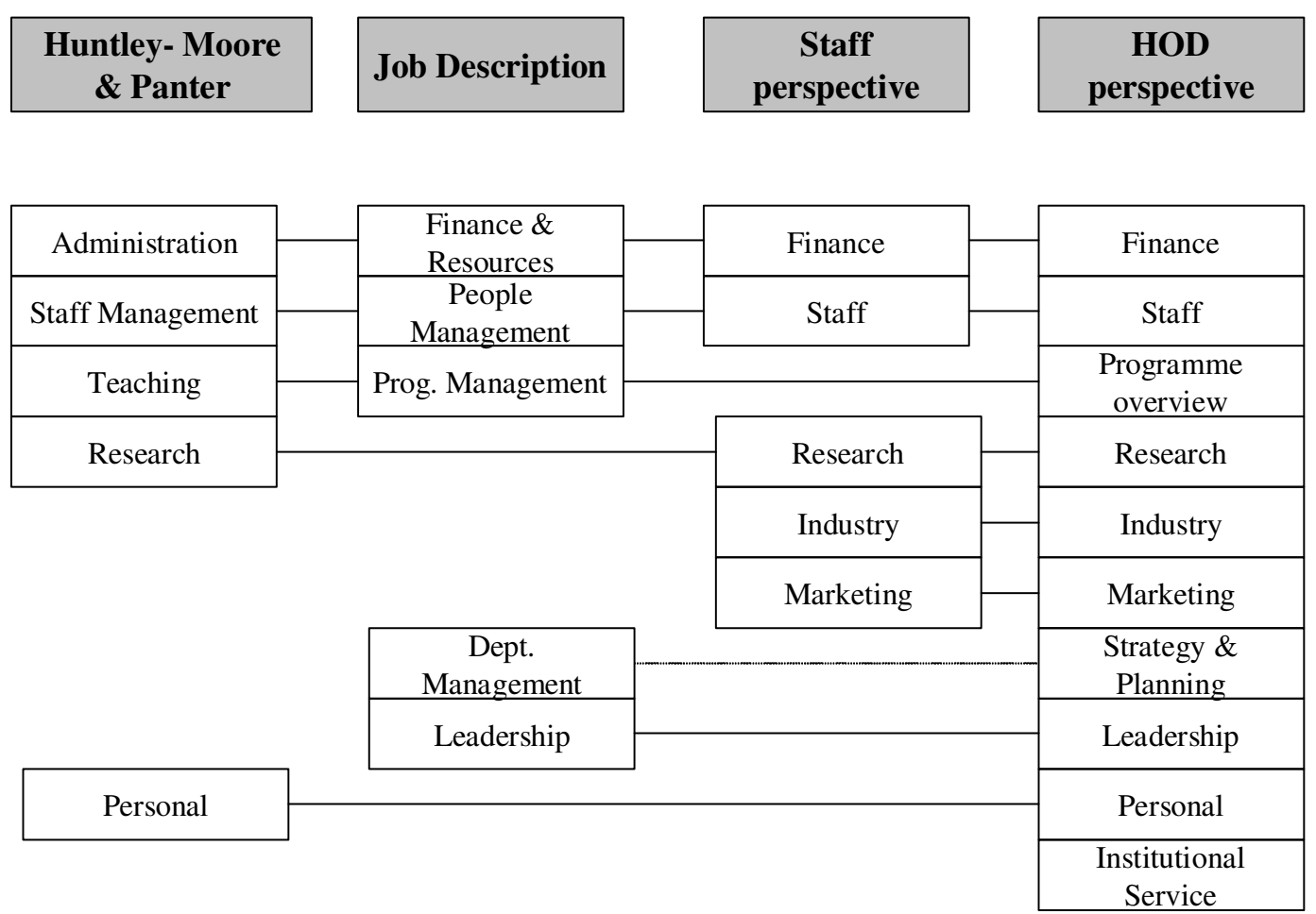

Figure 1 - Four perspectives of the HOD's role

amount of administration. This category of work is least likely to contain elements of change and innovation as it is usually prescribed by the administrative authorities of the institution.

It can be concluded from above and the details contained in the source documentation, that change and innovation is not clearly evident in the documentation that are used in practice at the institution. It must however be acknowledged that change and innovation might be and probably is implied to ensure success in each of the areas that the HOD is involved in. Clearly should one considered a broader range of tasks for HODs in further studies of the role of the HOD, but also the environment of organization.

\section{Self-Assessment Regarding the Hierarchy and Organization}

The same organization commenced with the overall review and change of the organizational hierarchies during 2003. The institution is challenged by a gradual reduction in student numbers, challenges by Private Training Enterprises, pockets of concerns about academic outcomes, possible shortcomings in current offerings and low staff morale. The review of the academic area of the hierarchy was undertaken after designs for the rest of the organization (what is also called the "Support Functions") has been completed and implementation was under way.

A survey was conducted inviting all staff to participate. This was followed by a series of focus group meetings where the same question was put to all attendees: "When considering the institution's organization hierarchy, please identify Strengths, Weaknesses, Opportunities and Constraints". The biggest strength was perceived as "Current Staff" - talents and leadership, existing synergies in clusters and a sense of identity and solidarity that provides ( $46 \%$ of responses), good 
programmes and a good hierarchy in the faculties (23\% of responses). The major weakness is "Internal Relationships", especially interdepartmental cooperation and joint ventures ( $22 \%$ of responses), workload and systems effect on staff (17\%), workload profile (little time, cumbersome systems and diverse activities) (12\%). Opportunities apparently exist to improve relationships in general ( $48 \%$ of responses), especially specific opportunities to improve external connectivity (29\%), and possibilities to review and improve the business management of programmes. Constraints to achieve this include internal bureaucratic impositions ( $73 \%$ of responses), external bureaucratic and systemic constraints (19\%), and high workload of teaching staff that is even degrading the quality of current teaching.

References were frequently made to the broad environmental conditions that typically were not supportive of change, innovation and improvement, such as complex bureaucracy, high workload and constraint relationships. Perceived strengths related to the matters that are operationally managed by the HODs - departmental team building, organization and programme health. Perceived weaknesses and constraints are related to matters dictated to HODs, such as staffing levels that result in workload problems, bureaucracy imposed by TEC and Support Functions (supposedly approved by Deans) and unsatisfactory inter-department cooperation (largely influenced by financial performance targets set for HODs and resource allocation policies along departmental lines).

Clearly the HOD is the person that manages the competing demands from executive/Deans and staff. The change, innovation and improvement required for the institutions to be successful, must be managed by the HODs. For the HOD of the ICT department, this would be a very high challenge when he/she is also faced with the challenges of ICT.

\section{Perceptions about the Roles of the Leaders}

Several focus group meetings were undertaken involving about 10\% of staff (most of them from academic units, at all levels of seniority) to obtain their perspectives regarding the current hierarchy before redesign commenced. This would be very important when the intention is to study the organization of staff for change and innovation as advised by Bates (2000), Kenny (2003), Huntley-Moore and Panter (2003) and Van Schoor (2003)).

When the focus groups were requested to identify three key roles of Deans, HODs and Programme Leaders, they responded exceptionally similarly. Deans are perceived to be responsible for resource allocation and strategy alignment, the vision, coordination and integrity of specialist areas, and representing academic perspective on executive strategic level. HODs are expected to look after staffing welfare (staff management), budget and financial viability, and strategy and department overview. This bears much similarity with the views previously mentioned in this paper about the role of HODs. Programme leaders are considered to be caretakers of student welfare by looking after student administration, timetabling of courses and the programmes quality management system.

Before considering implications of this response, one should take not of requirements by government. The Tertiary Education Commission (TEC) emphasizes two groups of key outcomes of the activities of ITPs, namely Academic and Financial. Both of these are visible in the lists above. TEC also emphasizes that ITPs should change internal activities were necessary in order to ensure success for these two outcomes. Again it is clear that all three levels of management must be working together to achieve changes in Academic or Financial outcomes. But it is also clear that the HOD is the point in the hierarchy where the Academic and Financial perspective become integrated - the point of fusion.

In above perspective, the Deans don't manage the change initiatives - their role is more transactional in nature as spokesperson. Instead, HODs will have to organize and oversee the projects for 
change, innovation and improvements. Some will be lead by the HOD, others by Programme Managers and some by members of department staff. The HOD is responsible for the outcomes regarding Academic and Financial Performance. Initiatives must be undertaken for change, innovation and improvement until both outcomes are achieved. Deans will ensure that change, innovation and improvement is underway in the departments, and staff expect the Dean to ensure there are enough resources for these initiatives. But the HOD is responsible for the outcome these initiatives and will have to reinitiate initiatives and manage staff until success is achieves in the Finance and Academic outcomes.

\section{Observations}

None of the documentation at the particular institution clearly indicates expectations regarding the role of the HOD in change and innovation. Official goals and objectives stated by the Dean for the HOD merely indicated that financial targets must be met, academic quality must be satisfactory and involvement with industry must be strengthened. When considering that there was a current shortfall on each of these goals to begin with, it becomes clear that the HOD will need to undertake change and innovation initiatives with staff of the department in order to achieve the goals. These initiatives will not involve the Dean directly - the HOD must initiate and manage the initiatives, as will become clear in further paragraphs.

It is the perception of staff members that programme leaders manage academic matters ("student welfare") while the HOD typically manages business matters ("Staffing welfare"). But these matters are not mutually exclusive - it is in fact highly integrated. Changes to financial matters will most probably require involvement of the programme leaders for the (re-)consideration of academic matters. And changes to programmes may require changes to staffing arrangements and finance - at least a revisit to the department strategic plan. Clearly the HOD needs to be involved in the operational aspects of matters for proper integration, while the Dean needs not be involved at all.

Programme leaders are protected from the business perspective of the department in that it is the stated responsibility of HODs to look after financial matters, staff matters and business planning. Staff will also not be expecting of programme leaders to be involved in these matters. HODs on the other hand must be involved in the academic matters because it has consequences for the business issues. Clearly is the work of the HOD much more integrated with that of the programme leaders and staff in the department than with the world of the Dean.

When Bates (2000) therefore proposes that teachers themselves examine their won activities and critically reflect upon own practices, constraints and consequences, then it is up to the HOD to create the environment for them. And when Kenny $(2002,2003)$ advises that teaching staff be organized in self-managed project teams for action learning environments with formal, iterative development cycles, then again the HOD can not be far away. This is the situation because the HOD must manage the staff according to job descriptions, other formal documentation and the perception and expectation of staff.

In the organization pictured in the previous sections, it is also the role of the HOD to manage the transformational capacity of staff, ie. their ability to deal with change and innovation. Van Schoor (2003) called this the "Transformational Intelligence" (TQ) of staff - their motivation, understanding of processes, interpersonal relationships and creative activities for change and innovation. The process of dealing with resistance can be expedited by engaging employees and organizational units in the development of Transformational Intelligence (TQ). The Dean plays no role whatsoever in the departmental activities regarding change and innovation, even in crossdepartmental initiatives. It is the perception of staff in this institution that the Dean is far removed from the operational environment where change and innovation takes place. Overall leadership is 
expected of the HOD and hence it is up to the HOD to manage resistance to change and innovation by managing "Transformational Intelligence" of staff.

The role of programme leaders should however not be underestimated in this environment. They are not directly responsible for staff management, according to the documentation and perceptions of staff. However, in practice the programme leaders arrange and chair meetings of department staff where the "health" of the programme and its courses are discussed and appropriate action is taken by one of the members to fix problems or change the programme. Whether the HOD is present or not, the programme leader is managing change and innovation specifically related to the programme. These could be about academic matters, but also matters caused by changes by the HOD to financial, staffing and strategic arrangements.

Above observations indicate that the HOD will be challenged to be the integrator of strategic and operational activities, to be the point of fusion between these levels in the organization. The HOD works in matrix organization across the whole organization - reporting to the Dean as the line manager, but also aligning the department to the needs of other line and support functions. The downward perspective of the world of the HOD is complicated by arrangements whereby programme leaders manage quality of the academic programmes, while staff members are still managed by the HOD.

When considering that the typical department at this institution holds 20-40 staff members with three or more programmes, then the challenge for the HOD becomes even clearer. Clearly the organization design is very flat with many staff reporting directly to the HOD. This would require high involvement from the HODs to decide on the assignment for each staff member, but also even simply to know the performance of each staff member for meaningful discussions regarding performance management and development of staff.

One matter that has been mentioned previously should be revisited at this stage. This is the HOD's involvement in institutional service activities. Examples include Boards of Studies, Research Committees, Financial Committees, Advisory Committees, Working Groups and ad hoc project team members. Huntley-Moore \& Panter (2003) does not clearly include these activities in their category "Administration", possibly because it does not relate to the activities in and for the department. Many efficient and effective HODs might find themselves becoming increasingly involved in these and other activities, thereby leaving less time for the work directly benefiting the department, especially the initiatives for change and innovation.

In conclusion- - it is clear that the HOD is the person who would be responsible for creating the environment for change and innovation proposed by Bates (2000), Kenny $(2002,2003)$ and Van Schoor (2003). However, perceptions about the role of HODs at the particular institution appears to reflect many possible complexities that could restrain change and innovation activities required for success of the institution.

\section{Conclusion}

It appears that the performance criteria of ICT teaching staff at the institution studied might not be reflecting to extent of change and innovation required from ICT teaching staff. This is likely to result in an under-appreciation and under-valuation of the work done by ICT teaching staff. It is also likely to result in insufficient training and development of staff for dealing with and initiating change and innovation. The dynamic nature of ICT brings complexities to the IT department of each ITP that might at this stage be underestimated. Combined with the possible overloading of the Heads of Department, several problems may be experienced regarding change and innovation.

It is essential that resource allocation for ICT in higher education be reviewed at national and institutional level. This is a given and a high necessity, as explained by Morrison (2001) and others. 
There could be emphasis and initiatives to measure actual workload to support lobbying for reviews of resource allocation, but it is also important to improve current efficiencies simultaneously. The HOD and ICT staff should still attempt to improve change, innovation and improvement of the department in the current environment. The ITP sector, and perhaps the whole higher education, could benefit from tackling this challenge systematically.

A visible indication that the problem is being tackled systematically in the sector would be when the number of publications focusing on improving the effort of tutors to achieve the same academic outcome, increases. Specific topics would include revision of curricula, the effects of teaching approaches, increased use of junior (cheaper) assistants and more self-directed learning. The use of new technologies, taking advantage of the learning styles of students, efficiency of automated assessment and sharing of best practices across institutions are also indicative that work is done systematically to achieve a situation where tutors spend less time on teaching duties. Reference to previous publications and case experiences in the sector building on previous experiences elsewhere would indicate that iterative development is under way in the community, as recommended by Kenny (2003).

ITPs and other higher education institutions in New Zealand (preferably Australasia) could seriously consider the possibility of national movements similar to that of the LEAGUE in America. The LEAGUE is an association of community colleges that promotes change and innovation in the college environment of America. It operates alongside AACC (the American Association of Community Colleges). Improvement and innovations in teaching and the use of ICT in the college environment are published and shared in annual conference workshops. New technologies are demonstrated and teams meet to work on improving the use of current technologies. The possibility could be explored to formulate a research proposal for special funding by government, since the purpose here is to achieve a situation where the output of the ITP sector is increased without proportionate investment in production facilities.

Inside the institutions, HODs should direct staff members towards research activities that would achieve the above outcomes. It can be emphasized in institutions that these initiatives can help to improve staff's won working environment. Special emphasis is required on the need for staff to be involved in the whole process of change experiments, for staff to examine their own activities and then critically reflect on own practices, environment constraints and overall consequences (Bates, 2000). A brief summary of the experiment should afterwards be documented to plan the next intervention and to progress into a paper at the national conference or in a journal. This approach would indicate that staff members are involved in self-directed organizational learning and development, as recommended by Bates (2000) and Kenny (2002, 2003).

More use could also be made from the committees overseeing programmes at each institution. Programme Committees meet frequently to plan the programme, discuss student progress, approve student results, decide on interventions that might be required and review regulations. This group of academic staff could add an important goal or objective to their agenda, namely the improvement of resource efficiency. Discussions and decisions are documented as specified by institutional quality systems that are in operation to ensure that the guidelines of the Ministry of Education are met regarding quality management. This could be an ideal forum where academic quality is balanced with business goals such as financial performance. It would again also involve staff in organizational learning and improvement and be in line with advice of Bates (2000) and Kenny (2002, 2003).

Reward systems for promotions and salary movements should also be reviewed. In extreme cases like some of the highly unionized institutions in New Zealand, this will be critically important. Much more emphasis is required on the contribution to change and innovation, especially the contribution to reduce the workload and time commitments of tutors. Research publications on 
the topic are required, but implementation is much more important - the actual achievement of the ability of themselves and others to free time from teaching while still maintaining academic standards. Rewards need not be only the promotion to higher levels, but could include financial payments or other non-financial benefits such as free time. The principle might understandably be less appropriate for universities where fundamental research about ICT is very important.

But HODs and management of the institutions must also create the best environment for staff to participate in change, innovation and improvement. Staff could for example benefit from having templates for planning an experiment and writing up the results and a paper. They might also need brief training on experimentation and action learning in small groups to initiate and operate quick, iterative learning cycles. Since some staff at ITPs are not used to reading conference proceedings as they teach full-time, other staff in the department will have to help in this regard. And finally must the communication flow be open inside and across departments while an atmosphere of risk-reward is promoted by management.

The duties and activities of HODs themselves should be reviewed. HODs face a range of challenges related to change and innovation (e.g. Huntley-Moore \& Panter, 2003; Potgieter \& Ferguson, 2003; Ramsden, 1998), and the administrative load of HODs is very clear. This leaves little time for the HOD to lead these change and innovation initiatives, whereas close involvement of senior management typically leads to more success in education environments (Ramsden, 1998). Some operational matters and administration could be removed temporarily or shared by senior staff in the department. The situation at each institution might be different.

In conclusion - policy changes are required to improve resource allocation for ICT at national and institutional level. But while this is under way, we recommended that institutions (especially ITPs) undertake more directed and coordinated intervention in order to change, innovate and improve where possible. We need focus and action on both levels to improve the efficiency of the sector end enable more change and innovation in future.

Further research is advisable to define possible change and innovation arrangements in higher education environments, especially ICT departments in the unique environments of ITPs. This should then be followed by empirical study of perceptions of ICT staff about change and innovation, their current relevant activities and especially internal organization for change and innovation. This will require the development of suitable survey instruments to describe and measure activities.

It would also be interesting to learn if the challenges faced by ICT staff are larger than other departments and whether ICT academics respond differently to these challenges. This needs to be done across institutions in order to search for best practices that could be followed by other ITPs. The result of such a research project would be that ICT departments of ITPs will be able to advance much faster in their ability to develop capabilities for change and innovation.

\section{References}

Albertyn, F. (2003). Comparing possible e-processes. Annual conference Proceedings of the National Advisory Committee on Computing Qualifications, July 2003.

Bates, A.W. (2000). Managing technological change: Strategies for college and university leaders. San Francisco: Jossey-Bass.

Bruce-Ferguson, P. (1999). Developing a research culture in a polytechnic: An action research case study. Unpublished doctoral thesis, University of Waikato. Retrieved 23 May 2003 from http://www.wintec.ac.nz/files/research\%20connections/phdthesis.doc 


\section{Exploring Change and Innovation by ICT Teaching Staff}

Bruce-Ferguson, P. (2003). How/Can we do it all? Annual conference proceedings of HERDSA (Higher Education Research and Development Society of Australasia Inc.), July 2003, Christchurch, New Zealand. Retrieved 20 July 2003 from http://surveys.canterbury.ac.nz/herdsa03

Burrel, C. (2003). Observing novice programmer skill development: A micro-world that supports objectoriented programming and usage data visualization. Third International Conference On Science, Mathematics and Technology Learning, Jan 15-18, 2003, East London, South Africa.

Chamberlain, B., Hope, B. G. (2003). Integrating international students into computing classes: issues and strategies. Annual conference Proceedings of the National Advisory Committee on Computing Qualifications, July 2003.

Clarke, R., \& Roper, P. (2003). Using a third party language with Microsoft.net. Annual conference Proceedings of the National Advisory Committee on Computing Qualifications, July 2003.

Connolly, T., \& Cleary, D. (2003). The development of a concurrent English-IT programme for international students. Annual conference Proceedings of the National Advisory Committee on Computing Qualifications, July 2003.

Galliers, R., \& Lard, F. (1987). Choosing appropriate information systems research methodologies. Communications of the ACM, 30 (11), 161-164.

Gilbert, J. (1994). The construction and reconstruction of the concept of the reflective practitioner in the discourses of teacher professional development. International Journal of Science Education, 16 (5), 511-522.

Hu, M. (2003). A case study in teaching adult student computer programming. Annual conference Proceedings of the National Advisory Committee on Computing Qualifications, July 2003.

Huntley-Moore, S., \& Panter, J. (2003). Does discipline matter? Issues in the design and implementation of management development programmes for head of academic departments. Annual conference proceedings of HERDSA (Higher Education Research and Development Society of Australasia Inc.), July 2003, Christchurch, New Zealand. Retrieved 20 July 2003 from http://surveys.canterbury.ac.nz/herdsa03

ICT Taskforce. (2002). Braking through the barriers. ICT Taskforce. November 2002. Retrieved 5 June 2003 from www.industrytaskforces.govt.nz

ITP. (2003). ITP sector charter and profile brochures. Retrieved 15 November 2003 from www.apnz.ac.nz

Jamieson, J. (2003). Modeling layers of artificial intelligence within a virtual world. Annual conference Proceedings of the National Advisory Committee on Computing Qualifications, July 2003.

Kearny, P., \& Skelton, S. (2003). Teaching technology to the Playstation generation. Annual conference Proceedings of the National Advisory Committee on Computing Qualifications, July 2003.

Kennedy, D. (2003). Relaxing with XML structures. Annual conference Proceedings of the National Advisory Committee on Computing Qualifications, July 2003.

Kenny, J. (2002). Managing innovation in educational institutions. Australian Journal of Educational Technology, 18 (3), 359-376.

Kenny, J. (2003). A research-based model for managing strategic educational change and innovation projects. Annual conference proceedings of HERDSA (Higher Education Research and Development Society of Australasia Inc.), 6-9 July 2003, Christchurch, New Zealand. Retrieved 20 July 2003 from http://surveys.canterbury.ac.nz/herdsa03

Kolb, D. (1984). Experiential learning: Experience as the source of learning and development. Engelwood Cliffs, NJ: Prentice-Hall.

Li, X. (2003). Applying adult learning principles in teaching a challenging course. Annual conference Proceedings of the National Advisory Committee on Computing Qualifications, July 2003. 
Mann, S., Davies, C., \& McGregor, G. (2003). The role of literacy in the IT curriculum. Annual conference Proceedings of the National Advisory Committee on Computing Qualifications, July 2003.

Morrison, I. (2001). ICT, The information economy and education. Paper presented as guest speaker at the annual conference of NACCQ, New Zealand. (Not in Proceedings of the Annual Conference of NACCQ, 2003)

NACCQ. (2003). Annual conference proceedings of the National Advisory Committee on Computing Qualifications, July 2003.

Nijsse, J.P., Whiddett, R.J., \& Atkins, C.F. (2003). Logical relational datamodeling through normalization. Annual conference Proceedings of the National Advisory Committee on Computing Qualifications, July 2003.

Pascoe, R. (2003). Is there a MOUS in your house? Annual conference Proceedings of the National Advisory Committee on Computing Qualifications, July 2003.

Paua, F. (2003). Global diffusion of ICT: A progress report. Retrieved 12 December 2004 from www.weforum.org

Pears, R., \& Mansfield, M. (2003). Approximate computation of multidimensional aggregates in a data warehouse. Annual conference Proceedings of the National Advisory Committee on Computing Qualifications, July 2003.

Potgieter, B.C. (1997). Service management of the information technology infrastructure. Unpublished doctoral thesis, Department of Informatics, University of Pretoria.

Potgieter, B.C., \& Herselman, M. (2003). Leading academic change management: A case study of faculty formation. Annual conference Proceedings of the National Advisory Committee on Computing Qualifications, July 2003.

Potgieter, B.C., \& Jansen van Vuuren, J. (2003). Specialization in ICT fields. Annual conference Proceedings of the National Advisory Committee on Computing Qualifications, July 2003.

Potgieter, B.C., \& Bruce-Ferguson, P. (2003). Is there a need to assist HODs manage change and innovation projects? New Zealand Applied Business Education Conference, 30 Sep - 2 Oct 2003.

Ramsden, P. (1998): Learning to lead higher education. London and New York: Routledge.

Robbins, P. (2003). The dot net experience. Annual conference Proceedings of the National Advisory Committee on Computing Qualifications, July 2003.

Roberton, G., Ross, J. (2003). NACCQ qualifications - Fifteen years at the forefront of New Zealand ICT education - What's on the horizon? Proceedings of the annual conference of NACCQ, July 2003.

Roggio, F.R. (2003). Use cases and traceability: a marriage for improved software quality. Annual conference Proceedings of the National Advisory Committee on Computing Qualifications, July 2003.

Strode, D. (2003). Using the UML to describe design patterns. Annual conference Proceedings of the National Advisory Committee on Computing Qualifications, July 2003.

TAMU. (2002). Tertiary Advisory Monitoring Unit. Retrieved July 2003 from http://www.minedu.govt.nz/web/document/document_page.cfm?id=4669

Van Schoor, A. (2002). Our response to the transformational imperative: The role of transformational intelligence in facilitating the process. Paper presented at the Transformation Workshop, Johannesburg, South Africa.

Van Schoor, A. (2003). Learning to overcome resistance to change in higher education: The role of transformational intelligence in the process. Annual conference Proceedings of HERDSA (Higher Education Research and Development Society of Australasia Inc.), July 2003, Christchurch, New Zealand. Retrieved 20 July 2003 from http://surveys.canterbury.ac.nz/herdsa03 
Walker, M. (1993). Developing the theory and practice of action research: A South African case. Educational Action Research, 1(1), 95 - 110

Wen, J., Sathu, H., \& Joyce, D. (2003). Adaptive strategy for voice over internet protocol in New Zealand. Annual conference Proceedings of the National Advisory Committee on Computing Qualifications, July 2003.

Yin, R. (1989) Case study research: design and methods. Newbury Park, CA: Sage Publications.

Young, A., \& Huggard, G. (2003). Designing new computer laboratories: Fresh ideas and new layouts. Annual conference Proceedings of the National Advisory Committee on Computing Qualifications, July 2003.

\section{Biography}

Christo Potgieter holds degrees in Computer Science, Management and Informatics, with the latter to doctoral level. Presented more than 30 conference papers on IT Service Management, ICT teaching and Education Management on most of the continents. Forums include national conferences for presentation of research by higher education, national conferences regarding ICT teaching, practice-based conferences for industry and international ICT conferences. Papers were accepted on a mix of abstract review, full peer review and double blind review. Examined Masters and Doctoral thesis's, lead Masters students and performed paper reviews for international conferences. Member of institutional committees related to institutional management and research. Obtained government funding for research project on IT Service Management for 2002. Two decades of work experience, the majority in industry (concluding period as a Deputy General Manager) and recent years in higher education (Associate Professor and Head of Department). 